\title{
Worldwide prevalence and risk factors for feline hyperthyroidism: A review
}

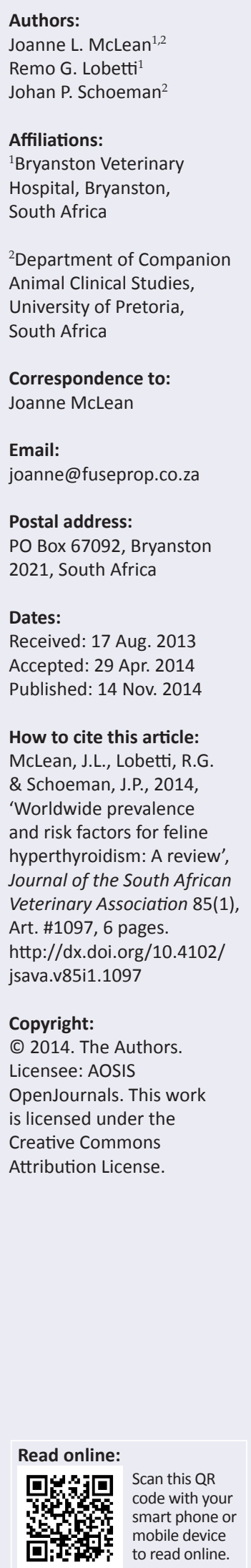

Since first reported in the late 1970s, there has been a steady but dramatic increase in the worldwide prevalence of hyperthyroidism in cats. It is now regarded as the most common feline endocrine disorder, with diabetes mellitus coming a close second. Not only is there evidence for an increased worldwide prevalence of feline hyperthyroidism, but also for geographical variation in the prevalence of the disease. Despite its frequency, the underlying cause(s) of this common disease is or are not known, and therefore prevention of the disease is not possible. Due to the multiple risk factors that have been described for feline hyperthyroidism, however, it is likely that more than one factor is involved in its pathogenesis. Continuous, lifelong exposure to environmental thyroid-disruptor chemicals or goitrogens in food or water, acting together or in an additive fashion, may lead to euthyroid goitre and ultimately to autonomous adenomatous hyperplasia, thyroid adenoma and hyperthyroidism. This review aims to summarise the available published evidence for the changes observed in the worldwide prevalence of the disease, as well as risk factors that may contribute to development of hyperthyroidism in susceptible cats.

\section{Introduction}

Feline hyperthyroidism (thyrotoxicosis) is a multisystemic disorder arising from excess production of the active thyroid hormones (tri-iodothyronine [T3] and/or thyroxine [T4]) from an abnormally functioning thyroid gland (Mooney 2010). Approximately $97 \%-99 \%$ of cases result from benign nodular hyperplasia, adenomatous hyperplasia or adenoma of the thyroid gland (Gunn-Moore 2005). In 70\% - 75\% of cases both thyroid glands are affected. Only 1\% - 3\% of cases are caused by mild to moderately malignant thyroid carcinoma (Gunn-Moore 2005). The disease has been reported in cats of between 8 months and 22 years of age, with a mean age of 13 years (Gordan et al. 2003; Peterson, Randolf \& Mooney 1994). Only 5\% of hyperthyroid cats are younger than 10 years at time of diagnosis (Peterson et al. 1994).

Clinically and histopathologically the disease resembles toxic nodular goitre of humans, a disease of the elderly that is more common in iodine-deficient areas (Edinboro, Scott-Moncrieff \& Glickman 2004). Over the past 33 years the prevalence of thyroidal pathological abnormalities has steadily but dramatically increased in the worldwide cat population. However, despite its frequency the underlying cause(s) of the disorder is or are not known, and thus it is unclear how to prevent it.

\section{Worldwide prevalence}

Feline hyperthyroidism appears to be a relatively 'new' disorder, first described in 1979 and 1980 by investigators in New York and Boston (Holzworth, Theran \& Carpenter 1980; Peterson et al. 1981). Before that time, although pathology studies had sometimes identified thyroid nodules or masses in cats, these had not commonly been found and were rarely, if ever, associated with clinical signs (Leav et al. 1976; Lucke 1964). Since these initial descriptions several studies have documented marked, steady increases in the prevalence of the disease in the cat population across the world with time. For example, in North America it increased from $0.3 \%$ in 1979 to $4.5 \%$ in 1985, and from $0.1 \%$ in 1978-1982 to $2 \%$ in 1993-1997, whilst in Germany it increased from $0.2 \%$ in $1987-1994$ to $2.6 \%$ in 1998 (Edinboro, Scott-Moncrieff, Janovitz, Thacker \& Glickman 2004; Kraft \& Buchler 1999; Scarlett, Moise \& Ray 1998).

This disorder is now not only recognised as the most common endocrinopathy of the cat, but one of the more frequently diagnosed disorders in small animal practice throughout North America, the United Kingdom (UK), Western Europe, Australia, New Zealand and Japan (Mooney 2010; Olczak et al. 2005; Peterson \& Ward 2007). Although a number of factors such as increased awareness, easier availability of thyroid hormone assays and ageing of the cat population may have contributed to the increase in diagnosis of feline hyperthyroidism observed, they 
are unlikely solely to account for the rapid and dramatic increase in prevalence of the disease (Edinboro, ScottMoncrieff \& Glickman 2004).

Little is known about the distribution or determinants of feline hyperthyroidism, and there are very few reported incidence rates or prevalence estimates (De Wet et al. 2009). Epidemiological studies that have been performed clearly suggest that not only is there evidence for an increased prevalence of feline hyperthyroidism, but also for geographical variation in the prevalence of the disease (Scarlett et al. 1998). Anecdotal reports suggest that hyperthyroidism has been diagnosed commonly in many countries or areas, such as North America, the UK and New Zealand, but much less commonly in other areas, such as Scandinavia and Hong Kong (Sparkes 2012). However, lack of good, detailed studies evaluating comparable cat populations in different countries indicates that definitive data are generally lacking (Sparkes 2012).

Nevertheless, some studies have provided convincing evidence of genuine geographical variations. In one 2005 study the incidence of hyperthyroidism in cats over 9 years of age seen at a London clinic and five clinics in Spain over a 3-year period was compared. Clinics in both Spain and the UK had a similar prevalence of cats aged over 9 years of age in their population ( $16.4 \%$ and $20.1 \%$ respectively). The study showed a significant difference in incident rates, with $11.92 \%$ in the UK versus 1.5\% in Spain (Wakeling, Melian \& Font 2005). Other prevalence studies have also substantiated the fact that there may be quite marked differences between geographical areas. The hospital prevalence amongst cats over 8 years of age in an urban population in Germany was noted as $11.4 \%$ in a 2006 study (Sassnau 2006). In Japan, a prevalence of $8.9 \%$ was reported in cats older than 9 years (Miyamoto, Miyata \& Kurobane 2002) in 2002, whilst a prevalence of $6 \%$ in apparently healthy cats over 9 years of age was reported in the UK in 2011 (Wakeling, Elliott \& Syme 2011), with a prevalence of $3.93 \%$ found in cats over 10 years of age in Hong Kong in 2009 (De Wet et al. 2009).

In terms of the situation in South Africa, no prevalence studies have been performed to date. It is the author's opinion, however, that hyperthyroidism in cats has only relatively recently been recognised, diagnosed and reported (2001/2002) in South Africa, and its prevalence appears to be on the increase.

\section{Risk factors}

Several epidemiological studies have attempted to identify potential risk factors for feline hyperthyroidism, but a single dominant factor has to date not been identified (Edinboro, Scott-Moncrieff, Janovitz, Thacker \& Glickman 2004; Kass et al. 1999; Martin et al. 2000; Olczak et al. 2005; Scarlett et al. 1998). Genetic or hereditary factors and nutritional component(s) in cat food leading to metabolic thyroid dysfunction, or thyroid-disrupting compounds introduced into the environment or diet, are the potential risk factors that have been closely investigated (Peterson \& Ward 2007).

Several substantial epidemiological studies from the United States of America, UK, Hong Kong and New Zealand have revealed some contradictory results (De Wet et al. 2009; Edinboro, Scott-Moncrieff, Janovitz, Thacker \& Glickman 2004; Kass et al. 1999; Martin et al. 2000; Olczak et al. 2005; Scarlett et al. 1998; Wakeling et al. 2009). These include an increased risk in indoor cats, female cats, cats in multi-cat households, cats with dental disease (independent of age), use of topical flea preparations and pesticides, use of cat litter (not linked to increased risk in indoor cats), consumption of certain flavours of canned foods (fish or liver and giblet flavour) and in non-purebred cats. As studies have failed to consistently identify these risk factors, their significance remains uncertain (Sparkes 2012).

A number of published studies have also identified several common factors, including increased risk with age, decreased risk in Siamese and Himalayan cats, and increased risk in cats that consume canned cat food, especially pop-top canned food (Mooney 2010; Sparkes 2012). It must be noted that all of these above factors are mere epidemiological associations and cannot demonstrate cause and effect (Sparkes 2012).

\section{Genetic or hereditary factors}

In studying the pathogenesis of feline hyperthyroidism researchers have considered a number of cellular and genetic factors, including whether feline hyperthyroidism resembles human Graves' disease, the most common cause of hyperthyroidism in people (Caney 2012). Graves' disease is an auto-immune disorder in which circulating antibodies (thyroid-stimulating immunoglobulins [TSIs]) bind to thyroid-stimulating hormone (TSH) receptors and mimic $\mathrm{TSH}$, thereby promoting thyroid hormone production and secretion (Mooney 2002). Levels of TSIs are increased in people suffering from Graves' disease (Caney 2012). However, three separate studies in which two different techniques were used failed to show such TSIs in hyperthyroid cats (Brown et al. 1992; Kennedy, Thoday \& Mooney 1989; Peterson, Livingston \& Brown 1987). Interestingly, increased titres of thyroid growth-stimulating immunoglobulins (TGIs) have been demonstrated in hyperthyroid cats (Brown et al. 1992). These have also been found in a variety of human thyroid diseases. In cats there is no correlation between thyroid function and TGI activity in vitro and their role in the pathogenesis of feline hyperthyroidism remains unclear (Mooney 2002).

The expression of stimulatory and inhibitory G proteins has also been studied in feline hyperthyroidism. G proteins are activated following binding of TSH to its receptor and are part of the intracellular signalling processes, amongst them the signal to secrete thyroid hormones (Ward et al. 2005). Both inhibitory and stimulatory G proteins exist, and the balance between these controls how much thyroid hormone is produced by the cell (Hammer, Holt \& Ward 2000; Peterson \& Ward 2007; Ward, Windham \& Dise 2010). Stimulatory $G$ proteins result in an increase in cyclic 
adenosine monophosphate (cAMP) levels, whereas inhibitory $\mathrm{G}$ proteins result in a decrease in cAMP levels (Hammer et al. 2000; Peterson \& Ward 2007; Ward et al. 2010). If levels of cAMP are increased, there is increased cell activation and thyroid hormone production. One study showed that whilst expression of stimulatory $G$ proteins was the same from thyroid tissue from euthyroid and hyperthyroid cats, expression of inhibitory G proteins (Gi) was significantly lower in the hyperthyroid cats (Hammer et al. 2000; Ward et al. 2005). Another study, where expression of $\mathrm{Gi}_{1}, \mathrm{Gi}_{2}$ and $\mathrm{Gi}_{3}$ in enriched membrane preparations from thyroid glands was quantified, demonstrated that a decrease in $\mathrm{Gi}_{2}$ expression in particular decreases inhibition of adenyl cyclase and allows a relative increase in stimulatory G-protein expression. This results in increased amounts of cAMP and upregulation of thyroid hormone production (Ward et al. 2005). Another more recent study, however, evaluating alteration in ligandstimulated activity of $G$ proteins in thyroid gland cells of hyperthyroid cats, found that ligand-stimulated activation of $G$ proteins was the same in both hyperthyroid and euthyroid cats. Therefore alteration in inherent stimulatory and inhibitory $G$ proteins did not appear to be part of the pathogenesis of the disease in cats in this study (Ward et al. 2010).

Adenomatous thyroid tissue from hyperthyroid cats has also been demonstrated to retain its histopathogical appearance and to continue to grow and function when transplanted into nude mice, thus confirming its autonomous nature (Peter et al. 1987). Additionally, thyroid cells from hyperthyroid cats, cultured in TSH-free media, have also been shown to continue to grow and function (Peter et al. 1991). Thus it is clear that feline hyperthyroidism more closely resembles human toxic nodular goitre than Graves' disease. Somatic mutations of the TSH receptor gene are an important cause of human toxic nodular goitre in humans. Mutations affecting the TSH gene have been identified in some cats with hyperthyroidism, including some mutations that have also been reported in human hyperthyroidism (Watson et al. 2005).

Abnormal oncogene expression has also been hypothesised to have a potential role in the pathogenesis of feline hyperthyroidism (Peterson \& Ward 2007). Proto-oncogenes are found in normal cells, and over-expression could eventually lead to autonomous function. One study where thyroid tissue of 28 hyperthyroid cats was examined for expression of the oncogenes c-ras, bc12 and the tumour suppressor gene p53, using immunohistochemistry, revealed over-expression of the c-ras protein (Merryman et al. 1999). Gain of function mutations in this oncogene may play a role in the development of adenomatous hyperplasia (Mooney 2010).

\section{Environmental chemicals}

Exposure to environmental chemicals (e.g. pesticides, herbicides) is known to induce thyroid abnormalities in other species (Brucker-Davis 1998).Chemicals applied directly to the cat or the cat's environment have been associated with increased risk of hyperthyroidism in some epidemiological studies (Olczak et al. 2005; Scarlett et al. 1988). Regular exposure of cats to topical flea control products was also shown to be associated with increased risk of developing the disease. However, none of these studies were able to identify a specific commercial anti-flea product or ingredient associated with this risk.

\section{Cat litter}

An association was also found between the use of cat litter and development of hyperthyroidism (Kass et al. 1999). Moreover, no difference in risk was found amongst brands of litter, suggesting that any toxin or goitrogenic chemical present is common to most brands. In the absence of a clear explanation of the relation between litter use and hyperthyroidism, use of cat litter may simply be a marker for cats that primarily live indoors, receive better than average care, enjoy longer lives, and are more likely to reach the age at which cats develop the disease (Peterson \& Ward 2007).

\section{Dietary iodine and selenium}

Because of the dietary association, several studies have attempted to implicate iodine in the cause and progression of the disease (Johnson et al. 1992; Mumma et al. 1986).It has been postulated that wide swings in daily iodine or even low or high intake of iodine may contribute to development of thyroid disease in cats. Although circulating free T4 concentrations are acutely affected by varying iodine intake, more prolonged ingestion of high- or low-iodine diets has been shown to have no apparent effect on free T4 levels (Tarttelin et al. 1992). Therefore the role that iodine plays in the development of the disease remains unknown. Dietary iodine may have a modulatory effect on circulating thyroid hormone, but neither iodine excess nor deficiency can explain the development of thyroid adenomatous hyperplasia or the autonomous nature of hyperthyroidism in cats (Peterson \& Ward 2007).

Like iodine, selenium status could also potentially modify thyroid function. One study found no difference in selenium status in either euthyroid or hyperthyroid cats sampled from different geographical locations with high and low prevalence of hyperthyroidism, but did find that circulating selenium values in all cats in the study were approximately five times higher than values reported in either rats or humans (Foster et al. 2001). The reason for the high levels of selenium is unclear, but may possibly be a result of increased dietary intake in this species. The significance of this finding is, however, still not known.

\section{Other goitrogenic compounds}

Many other goitrogenic compounds can contribute to the development of adenomatous lesions in exposed cats (Mooney 2010). These may be of particular importance, because most are metabolised by glucuronidation, a metabolic pathway that is particularly slow in the cat (Mooney 2010). Most commercial cat foods contain relatively high levels of 
goitrogenic compounds (e.g. phthalates), and cats can also be exposed to many goitrogens (e.g. resourcenel, polyphenols, polychlorinated biphenols, polybrominated diphenyl ethers and isoflavones) in the environment (Peterson \& Ward 2007).

\section{Bisphenol A}

The polyphenolic compound bisphenol A (BPA), a building block of the epoxy resins commonly used for lining the interior of metal food cans to prevent corrosion, has been detected in 15 different canned cat foods (Moriyama et al. 2002). BPA is a chemical of concern, as it is a known endocrine disruptor and has been associated with various adverse health effects, including thyroid dysfunction in humans (Peterson 2012). Some of the toxic effects of BPA may in fact be derived from its structural similarity to thyroid hormones (Peterson 2012).

Chronic exposure to BPA may affect thyroid function through a number of potential mechanisms. BPA has been shown to bind directly to thyroid hormone receptors as well as acting to disrupt thyroid hormone action within cells by competitively displacing $\mathrm{T} 3$ from the receptor and thus suppressing activation of transcription of thyroid-regulated genes. By acting as a thyroid hormone receptor antagonist, BPA may work at the pituitary level to increase circulating TSH and thus lead to thyroid hyperplasia and ultimately goitre in susceptible cats (Peterson 2012). Exposure to BPA is thought to occur primarily through ingestion, and it is well established that residual BPA monomers migrate into the can contents during processing and storage (Peterson 2012).

Evidence of BPA contamination of canned foods for human use has been widely reported (Tsai 2006). In two studies evaluating pet foods most of the dog and cat foods were found to contain measurable levels of BPA, and one of these studies confirmed that the BPA in the food had in fact originated from the can coating (Kang \& Kondo 2002; Schecter et al. 2010; also see Peterson 2012). One large case-control study demonstrated an association between hyperthyroidism and cats fed from 'pop-top' cans (Edinboro, Scott-Moncrieff, Janovitz, Thacker \& Glickman 2004; also see Peterson 2012). Results of the study suggested that overall consumption of pop-top canned food at various times throughout a cat's life was associated with a greater risk of developing hyperthyroidism compared with feeding from pouches or sachets. Another case-control study carried out in the USA also found that cats that preferred to eat certain flavours of canned cat food (fish or liver and giblets flavour) were at a significantly greater risk of hyperthyroidism compared with cats that did not prefer these flavours (Martin et al. 2000).

\section{Soy isoflavones}

Polyphenolic soy isoflavones, in particular genistein and daidzein, have also been identified in almost $60 \%$ of cat foods tested, and have been shown to have negative effects on the pituitary-thyroid axis in both humans and rats (Court \& Freeman 2002). They are commonly used as dietary supplements and as a low-cost source of protein. Virtually all dry and semi-moist foods containing soy protein have high isoflavone content in concentrations sufficient to interfere with thyroid function and decrease synthesis of thyroid hormones (Doerge \& Sheehan 2002; also see Peterson 2012). Soy isoflavones inhibit the activity of thyroid peroxidase, a key enzyme in the synthesis of thyroid hormones, which liberates iodine for addition to thyroglobulin for production of T3 and T4. They also inhibit 5'-deiodinase activity - the enzyme that converts total T4 into the biologically active T3. By blocking the production of thyroid hormones, TSH secretion will be increased, leading to thyroid hyperplasia and possibly goitre (Doerge \& Sheehan 2002; also see Peterson 2012).

In a short-term (3 months) feeding study in clinically normal cats, those receiving the soy diet had higher total $\mathrm{T} 4$ and free $\mathrm{T} 4$ concentrations, but total $\mathrm{T} 3$ concentrations remained unchanged (White et al. 2004). These results indicate that short-term feeding of soy to normal cats has a measurable although modest effect on thyroid hormone homeostasis. Despite maintaining these normal hormone values, detectable urinary concentrations of the isoflavone genistein were found in 10 of the 18 cats in the study, suggesting that cats may have significant body burdens of this goitrogen. Of interest are studies in rats that demonstrate that feeding large amounts of soy isoflavones has little demonstrable effect on thyroid function (also see Peterson 2012). However, in the presence of iodine deficiency feeding soy has been shown to readily inhibit thyroid hormone secretion and induce goitre. Thus feeding of soy can cause goitre, but only in animals or humans consuming diets that are relatively deficient in iodine, or in those individuals who are otherwise predisposed to developing goitre because of exposure to other goitrogenic agents (Ikeda et al. 2001; also see Peterson 2012).

\section{Polybrominated diphenyl ethers}

Polybrominated diphenyl ethers (PBDEs) are synthetic bromide compounds that have been used as flame retardants in a variety of consumer products, such as electronics, furniture and textiles, for the past 30 years (Dye et al. 2007). Over this time they have also become major global and persistent organic contaminants that bio-accumulate in the environment, biomagnify up the food chain, and have been found in significant amounts in both animals and humans (Peterson 2012). The chemical structure and properties of PBDEs are similar to those of polychlorinated biphenyls (PCBs), which were banned in the USA in the late 1970s (Peterson 2012). Like PCBs, some of the toxic effects of PBDEs may derive from their structural similarities to thyroid hormones.

Studies performed in rats, mice and humans have shown that PBDEs clearly disrupt thyroid hormone metabolism. In rats and mice PBDEs lower free and total T4 concentrations in a dose-dependent manner, but have not been shown to affect circulating TSH concentrations (Hallgren \& Darnerud 2002; Hallgren et al. 2001; Zhou et al. 2001). Conversely, in humans, higher exposure to PBDEs has been shown to reduce serum TSH values and increase total T4 concentrations (Peterson 2012). Reports 
of environmental contamination with PBDEs were first published in 1979. This is coincident with the first veterinary case reports of feline hyperthyroidism, and thus they may play a role in pathogenesis of the disease in this species (Dye et al. 2007).

To date, multiple studies (three American and two Swedish) designed to determine whether body burdens of PBDEs in hyperthyroid cats were greater than those of nonhyperthyroid cats have shown that overall PDBEs levels in all cats are 20-100-fold greater than median levels found in human adults (Dye et al. 2000; Guo et al. 2012; Kupryianchyk et al. 2009; Mensching et al. 2012; Norrgran et al. 2012). However, none of the studies demonstrated an association between hyperthyroid cats and high serum PBDE levels. Two of the studies did show that serum PBDE concentrations in feral and outdoor cats are significantly lower than in clientowned and indoor cats, suggesting that house dust rather than diet is the most likely route of exposure to PBDEs in household cats (Guo et al. 2012; Mensching et al. 2012).

In a follow-up study investigators evaluated dust samples for PBDEs, and found significantly higher PBDEs in dust from homes of hyperthyroid cats compared with those of euthyroid cats (Mensching et al. 2012). A significant correlation was also found between high dust PBDE values and high serum total T4 concentrations. Overall, these studies show that cats can be highly exposed to PBDEs, presumably through ingestion of household dust during their normal grooming behaviour. These findings also provide compelling evidence for the possible role of PBDEs in the development of thyroid tumours and hyperthyroidism in cats, although additional investigations are certainly warranted (also see Peterson 2012).

In addition to the above, there are many other goitrogens and thyroid disruptors (e.g. perchlorates, PCBs, resorcinol, dioxins, fluoride, FD\&C red dye \#3) that cats can be exposed to through their diet, drinking water or the environment, that could contribute to the development of thyroid adenomatous hyperplasia and hyperthyroidism (Peterson 2012). Endocrine disruptors such as heavy metals (e.g. mercury) and chlorinated hydrocarbons (e.g. polyvinyl chloride [PVC]) have been reported as contaminants in commercial canned cat food (Mumma et al. 1986). Such agents generally cause goitre by acting directly on the thyroid gland to reduce thyroid hormone synthesis. The resultant low circulating total T4 leads to increased TSH secretion, which in turn leads to thyroid enlargement (Peterson 2012). Other goitrogens, however, act indirectly to alter the regulator mechanisms of the thyroid gland or the peripheral metabolism and secretion of certain thyroid hormones (Peterson 2012).

\section{Conclusion}

Despite its increasing frequency, the origin and underlying pathogenesis of feline hyperthyroidism is not known, and therefore definitive recommendations in terms of prevention of the disease cannot as yet be made. It has been postulated that immunological, infectious, nutritional (e.g. iodine), environmental (e.g. toxins or goitrogens) or genetic factors may interact to cause pathological changes. The substantial flaw in the logic of 'pointing the finger' at any one of these is how they could cause the disease to develop in cats on different continents within a relatively short period of time. The seemingly apparent variation in the geographical prevalence of hyperthyroidism in cats may in fact reflect differences in dietary, environmental or genetic factors.

Further research into the worldwide prevalence as well as the presence of possible causative factors would help to shed light on the cause and pathogenesis of this disease and lead to preventative measures. As far as the authors are aware, no prevalence studies have been done in South Africa, a geographical area in which, in the authors' opinion, hyperthyroidism in cats has only relatively recently been observed and reported, and the incidence of which appears to be on the increase.

\section{Acknowledgements Competing interests}

The authors declare that they have no financial or personal relationship(s) that may have inappropriately influenced them in writing this article.

\section{Authors' contributions}

J.L.M. (University of Pretoria) wrote the manuscript. R.G.L. (Bryanston Veterinary Hospital) and J.P.S. (University of Pretoria) made conceptual contributions.

\section{References}

Brown, R.S., Keating, P., Livingston, P.G. \& Bullock, L., 1992, 'Thyroid growth immunoglobulins in feline hyperthyroidism', Thyroid 2, 125-130. http://dx.doi. org/10.1089/thy.1992.2.125

Brucker-Davis, F., 1998, 'Effects of environmental synthetic chemicals on thyroid function', Thyroid 8, 827-856. http://dx.doi.org/10.1089/thy.1998.8.827

Caney, S., 2012, 'Where are we now? Pathogenesis, clinical signs and diagnosis of feline hyperthyroidism', in I. Becvarova \& H. Meyer (eds.), Feline hyperthyroidism: the rise and fall of thyroxine, Global Symposium Proceedings, Barcelona, Spain, May 09-11, 2012, pp. 9-12.

Court, M.H. \& Freeman, L.M., 2002, 'Identification and concentration of soy isoflavones in commercial cat foods', American Journal of Veterinary Research isoflavones in commercial cat foods', American Journal of
$63(2), 181-185$. http://dx.doi.org/10.2460/ajvr.2002.63.181

De Wet, C.S., Mooney, C.T., Thomson, P.N. \& Schoeman, J.P., 2009, 'Prevalence of and risk factors for feline hyperthyroidism in Hong Kong', Journal of Feline Medicine and Surgery 11, 315-321. http://dx.doi.org/10.1016/j.jfms.2008.08.001

Doerge, D.R. \& Sheehan, D.M., 2002, 'Goitrogenic and estrogenic activity of soy isoflavones', Environmental Health Perspectives 110(3), 349-353. http://dx.doi. org/10.1289/ehp.02110s3349

Dye, J.A., Venier, M., Zhu, L., Ward, C.R., Hites, R.A. \& Birnbaum, L.S., 2007, 'Elevated PBDE levels in pet cats: sentinels for humans?', Environmental Science and Technology 41, 6350-6356. http://dx.doi.org/10.1021/es0708159

Edinboro, C.H., Scott-Moncrieff, J.C. \& Glickman, L.T., 2004, 'Environmental risk factors for feline hyperthyroidism: Pet cats as potential sentinels for public health', Thyroid 14, 759 .

Edinboro, C.H., Scott-Moncrieff, J.C., Janovitz, E., Thacker, H.L. \& Glickman, L.T., 2004, 'Epidemiologic study of relationships between consumption of commercial canned food and risk of hyperthyroidism in cats', Journal of the American Veterinary Medical Association 224, 879-886. http://dx.doi.org/10.2460/ javma.2004.224.879

Foster, D.J., Thoday, K.L., Arthur, J.R., Nicol, F., Beatty, J.A., Svendsen, C.K. et al., 2001 , 'Selenium status of cats in four regions of the world and comparison with reported incidence of hyperthyroidism in cats in those regions', American Journa of Veterinary Research 62, 934-937. http://dx.doi.org/10.2460/ajvr.2001.62.934

Gordan, J.M., Ehrhart, E.J., Sisson, D.D. \& Jones, M.A., 2003, 'Juvenile hyperthyroidism in a cat', Journal of the American Animal Association 39, 67-71. http://dx.doi. org/10.5326/0390067 
Gunn-Moore, D., 2005, 'Feline endocrinopathies', Veterinary Clinics of North America: Small Animal Clinics 35, 171-210. http://dx.doi.org/10.1016/j.cvsm.2004.09.002

Guo, W., Park, J.S., Wang, Y., Gardner, S., Baek, C., Petreas, M. et al., 2012, 'High polybrominated diphenyl ether levels in Californian house cats: House dust http://dx.doi.org/10.1002/etc.1700

Hallgren, S. \& Darnerud, P.O., 2002, 'Polybrominated diphenyl ethers (PBDEs), polychlorinated biphenyls (PCBs) and chlorinated paraffins (CPS) in rats - testing interactions and mechanisms for thyroid hormone effects', Toxicology 177, 227243. http://dx.doi.org/10.1016/S0300-483X(02)00222-6

Hallgren, S., Sinjari, T., Hakansson, H. \& Darnerud, P.O., 2001, 'Effects of polybrominated diphenyl ethers (PBDEs) and polychlorinated biphenyls (PCBs) on thyroid hormone and Vitamin A levels in rats and mice', Archives of Toxicology 75 200-208. http://dx.doi.org/10.1007/s002040000208

Hammer, K.B., Holt, D.E. \& Ward, C.R., 2000, 'Altered expression of G proteins in thyroid gland adenomas obtained from hyperthyroid cats', American Journal of
Veterinary Research 61, 874-879. http://dx.doi.org/10.2460/ajvr.2000.61.874

Holzworth, J., Theran, P. \& Carpenter, J.L., 1980, 'Hyperthyroidism in the cat: Ten cases', Journal of the American Veterinary Medical Association 176, 345-353.

Ikeda, T., Nishikawa, A., Son, H.Y., Nakamura, H. \& Imazawa, T., 2001, 'Synergistic effects of high soy bean intake with iodine deficiency, but not sulpahadimethoxine or phenobarbital on rat thyroid proliferation', Japanese Journal of Cancer Research 92, 390-395. http://dx.doi.org/10.1111/j.1349-7006.2001.tb01107.x

Johnson, L.A., Ford, H.C., Tarttelin, M.F. \& Feek, C.M., 1992, 'lodine content of commercially-prepared cat foods', New Zealand Veterinary Journal 40, 18-20. http://dx.doi.org/10.1080/00480169.1992.35691

Kang, J.H. \& Kondo, F., 2002, 'Determination of bisphenol A in canned pet foods', Research in Veterinary Science 73, 177-182. http://dx.doi.org/10.1016/S00345288(02)00102-9

Kass, P.H., Peterson, M.E., Levy, J.K., Becker, D.V. \& Cowgill, L.D., 1999, 'Evaluation of environmental, nutritional and host factors in cats with hyperthyroidism',

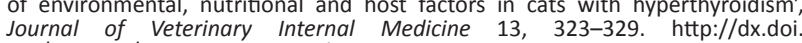
Journal of Veterinary Internal Medici
org/10.1111/j.1939-1676.1999.tb02189.x

Kennedy, R.L., Thoday, K.L. \& Mooney, C.T., 1989, 'Lack of thyroid stimulatory activity in the serum of hyperthyroid cats', Autoimmunology 3, 317-318. http://dx.doi. org/10.3109/08916938908997102

Kraft, W. \& Buchler, F., 1999, 'Hyperthyroidism: Incidence in the cat', Tierärztliche Praxis. Ausgabe K, Klientiere/Heimtiere 27, 386-388.

Kupryianchyk, D., Hovender, L., Jones, B., Lindqvist, N.G., Eriksson, S. \& Bergman, A., 2009, 'Hyperthyroidism, a new disease in cats- is it caused by exposure to environmental organic pollutants?', Organohalogen Compendium 71, 2720-2725.

Leav, I., Schiller, A.L., Rijnberk, A., Legg, M.A. \& Der Kinderen, P.J., 1976, 'Adenomas and carcinomas of the canine and feline thyroid', American Journal of Pathology and $61-122$

Lucke, V.M., 1964 'A histological study of thyroid abnormalities in the domestic cat', Journal of Small Animal Practice 5, 352-358. http://dx.doi. org/10.1111/j.1748-5827.1964.tb04261.x

Martin, K.M., Rossing, M.A., Ryland, L.M., Digiacomo, R.F. \& Freitag, W.A., 2000 'Evaluation of dietary and environmental risk factors for hyperthyroidism in cats', Journal of the American Veterinary Medical Association 217, 853-856. http:// dx.doi.org/10.2460/javma.2000.217.853

Mensching, D.A., Slater, J., Scott, J.W., Ferguson, D.C. \& Beasley, V.R., 2012, 'The feline thyroid gland: A model for endocrine disruption by polybrominated dipheny ethers (PBDEs)?', Journal of Toxicology and Environmental Health 75, 201-212. http://dx.doi.org/10.1080/15287394.2012.652054

Merryman, J.I., Buckles, E.L., Bowers, G. \& Nielsen, N.R., 1999, 'Overexpression of c-Ras in hyperplasia and adenomas of the feline thyroid gland: An immunohistochemical analysis of 34 cases', Veterinary Pathology 36, 117-124 http://dx.doi.org/10.1354/vp.36-2-117

Miyamoto, Y., Miyata, I. \& Kurobane, K., 2002, 'Prevalence of feline hyperthyroidism in Osaka and the Chugoku region', Journal of the Japanese Veterinary Medical in Osaka and the Chugok
Association 55, 289-292.

Mooney, C.T., 2002, 'Pathogenesis of feline hyperthyroidism', Journal of Feline Medicine and Surgery 4, 167-169. http://dx.doi.org/10.1053/jfms.2002.0177

Mooney, C.T., 2010, 'Hyperthyroidism', in S. Ettinger \& E. Feldman (eds.), Textbook of Veterinary Internal Medicine: Diseases of the Dog and Cat, pp. 1761-1779, W.B. Saunders, Philadelphia.

Moriyama, K., Tagami, T., Akamizu, T., Usui, T., Saijo, M., Kanamoto, N. et al., 2002 'Thyroid hormone action is disrupted by bisphenol A as an antagonist', Journal of Clinical Endocrinology and Metabolism 87(11), 5185-5190. http://dx.doi. org/10.1210/jc.2002-020209

Mumma, R.O., Rashid, K.A., Shane, B.S., Scarlettt-Kranz, J.M., Hotchkiss, J.H. \& Eckerlin, R.H., 1986, 'Toxic and protective constituents in pet foods', American Journal of Veterinary Research 47, 1633-1637.

Norrgran, J., Jones, B., Lindquist, N.G. \& Bergman, A., 2012, 'Decabromobiphenyl, polybrominated diphenyl ethers and brominated phenolic compounds in serum of cats diagnosed with the endocrine disease feline hyperthyroidism', Archives in Environmental Contaminants and Toxicology 63, 161-168. http://dx.doi. org/10.1007/s00244-012-9750-y
Olczak, J., Jones, B.R., Pfeiffer, D.U., Squires, R.A., Morris, R.S. \& Markwell, P.J., 2005, 'Multivariate analysis of risk factors for feline hyperthyroidism in New Zealand', New Zealand Veterinary Journal 53, 53-58. http://dx.doi. org/10.1080/00480169.2005.36469

Peter, H.J., Gerber, H., Studer, H., Becker, D.V. \& Peterson, M.E., 1987, 'Autonomy of growth and of iodine metabolism in hyperthyroid feline goiters transplanted onto nude mice', Journal of Clinical Investigation 80, 491-498. http://dx.doi. org $/ 10.1172 / \mathrm{JCl} 113097$

Peter, H.J., Gerber, H., Studer, H., Peterson, M.E., Becker, D.V. \& Groscurth, P., 1991 'Autonomous growth and function of cultured thyroid follicles from cats with spontaneous hyperthyroidism', Thyroid 1, 331-337. http://dx.doi.org/10.1089/ spontaneous hype
thy.1991.1.331

Peterson, M.E., 2012, 'Hyperthyroidism in cats: What's causing this epidemic of thyroid disease and can we prevent it?', Journal of Feline Medicine and Surgery 14, 804-818. http://dx.doi.org/10.1177/1098612X12464462

Peterson, M.E., Kintzer, P.P., Cavanagh, P.G., Fox, P.R., Ferguson, D.C., Johnson, G.F. et al., 1981, 'Feline hyperthyroidism: Pretreatment clinical and laboratory evaluation of 131 cases', Journal of the American Veterinary Medical Association 183, 103-110.

Peterson, M.E., Livingston, P. \& Brown, R.S., 1987, 'Lack of circulating thyroid stimulating immunoglobulins in cats with hyperthyroidism', Veterinary Immunology an Immunopathology 16, 277-282. http://dx.doi.org/10.1016/0165-2427(87)90024-9

Peterson, M.E., Randolf, J.F. \& Mooney, C.T., 1994, 'Endocrine disease', in R.G. Sherding (ed.), The Cat: Diseases and Clinical Management, pp. 1416-1452, Churchill Livingstone, New York.

Peterson, M.E. \& Ward, C.R., 2007, 'Etiopathologic findings of hyperthyroidism in cats', Veterinary Clinics of North America: Small Animal Practice 37, 63-645. http://dx.doi.org/10.1016/j.cvsm.2007.05.001

Sassnau, R., 2006, 'Epidemiological investigation on the prevalence of feline hyperthyroidism in an urban population in Germany', Tierärztliche Praxis, Kleintiere 34, 450-457.

Scarlett, J.M., Moise, N.S. \& Ray, J., 1998, 'Feline hyperthyroidism: A descriptive and case control study', Previews of Veterinary Medicine 6, 295-309. http://dx.doi org/10.1016/0167-5877(88)90041-4

Schecter, A., Malik, N., Haffner, D., Smith, S., Harris, T.R., Paepke, O. et al., 2010, 'Bisphenol A in US food', Environmental Science and Technology 44(24), 94259430. http://dx.doi.org/10.1021/es102785d

Sparkes, A., 2012, 'Where are we now? Historical and epidemiological aspects of feline hyperthyroidism', in I. Becvarova \& H. Meyer (eds.), Feline Hyperthyroidism: The Rise and Fall of Thyroxine, Global Symposium Proceedings, Barcelona, Spain, May 09-11, 2012, pp. 5-8.

Tarttelin, M.F., Johnson, L.A., Cooke, R.R., Ford, H.C. \& Feek, C.M., 1992, 'Serum free thyroxine levels respond inversely to changes in levels of dietary iodine in the domestic cat', New Zealand Veterinary Journal 40, 66-68. http://dx.doi. org/10.1080/00480169.1992.35700

Tsai, W.T., 2006, 'Human health risk on environmental exposure to bisphenol-A: A review', Journal of Environmental Science, Health, Environmental Carcinogens and Ecotoxicological Review 24, 225-255. http://dx.doi. org/10.1080/10590500600936482

Wakeling, J., Elliott, J. \& Syme, H., 2011, 'Evaluation of predictors for the diagnosis of hyperthyroidism in cats', Journal of Veterinary Internal Medicine 25, 1057-1065. http://dx.doi.org/10.1111/j.1939-1676.2011.00790.x

Wakeling, J., Everard, A., Brodbel, D., Elliott, J. \& Syme, H., 2009, 'Risk factors for feline hyperthyroidism in the UK', Journal of Small Animal Practice 50, 406-414. http:// dx.doi.org/10.1111/j.1748-5827.2009.00756.x

Wakeling, J., Melian, C. \& Font, A., 2005, 'Evidence for differing incidences of feline hyperthyroidism in London, UK and Spain', Proceedings of the 15th ECVIM-CA Congress, Glasgow, Scotland, September 01-03, 2005, p. 220.

Ward, C.R., Achenbach, S.E., Peterson, M.E., Drobatz, K.J. \& Holt, D., 2005, 'Expression of inhibitory $\mathrm{G}$ proteins in adenomatous thyroid glands obtained from hyperthyroid cats', American Journal of Veterinary Research 66, 1478-1482. from hyperthyroid cats', American Journal of
$\mathrm{http}: / / \mathrm{dx}$.doi.org/10.2460/ajvr.2005.66.1478

Ward, C.R., Windham, W.R. \& Dise, D., 2010, 'Evaluation of activation of G proteins in response to thyroid stimulating hormone in thyroid gland cells from euthyroid and hyperthyroid cats', American Journal of Veterinary Research 71, 643-648. http://dx.doi.org/10.2460/ajvr.71.6.643

Watson, S.G., Radford, A.D., Kipar, A., Ibarrola, P. \& Blackwood, L., 2005, 'Somatic mutations of the thyroid-stimulating hormone receptor gene in feline hyperthyroidism: parallels with human hyperthyroidism', Journal of Endocrinology hyperthyroidism: parallels with human hyperthyroidism

White, H.L., Freeman, L.M., Mahony, O., Graham, P., Hao, Q. \& Court, M.H., 2004, 'Effect of dietary soy on serum thyroid hormone concentrations in healthy adult cats', American Journal of Veterinary Research 65(5), 586-591. http://dx.doi. org/10.2460/ajvr.2004.65.586

Zhou, T., Ross, D.G., Devito, M.J. \& Crofton, K.M., 2001, 'Effects of short-term in-vivo exposure to polybrominated diphenyl ethers on thyroid hormones and hepatic enzyme activities in weanling rats', Toxicological Science 61, 76-82. http://dx.doi. org/10.1093/toxsci/61.1.76 